\title{
Role of Shear Keys in Seismic Behavior of Bridges Crossing Fault-Rupture Zones
}

\author{
Rakesh K. Goel, and Anil K. Chopra
}

\begin{abstract}
This paper examines the role of shear keys at bridge abutments in the seismic behavior of "ordinary" bridges. The seismic responses of bridges subjected to spatially uniform and spatially varying ground motions for three shear-key conditions-nonlinear shear keys that break off and cease to provide transverse restraint if deformed beyond a certain limit; elastic shear keys that do not break off and continue to provide transverse restraint throughout the ground shaking; and no shear keys-are examined. Results show that seismic demands for a bridge with nonlinear shear keys can generally be bounded by the demands of a bridge with elastic shear keys and a bridge with no shear keys for both types of ground motions. While ignoring shear keys provides conservative estimates of seismic demands in bridges subjected to spatially uniform ground motion, such a practice may lead to underestimation of some seismic demands in bridges in fault-rupture zones that are subjected to spatially varying ground motion. Therefore, estimating the upper bounds of seismic demands in bridges crossing fault-rupture zones requires analysis for two shear-key conditions: no shear keys and elastic shear keys.
\end{abstract}

CE Database subject headings: Earthquakes; Seismic effects; Bridge abutments; Elasticity; Shear.

\section{Introduction}

Reinforced-concrete bridges in California typically consist of a multicell box girder deck supported on abutments at two ends and single or multiple intermediate bents. The abutment consists of two wing walls, a back wall, shear keys (exterior), a seat, footing, and piles, if needed (Fig. 1). The shear keys at the abutment of bridges are designed to provide transverse restraint to the superstructure during service load and moderate earthquakes. During the maximum considered earthquake (MCE), however, the shear keys are designed as sacrificial elements to protect the abutment stem wall, wing walls, and piles from damage, implying that the shear keys will break off before damage occurs in piles or abutment walls. The current California Department of Transportation (CALTRANS) seismic design criteria (SDC) for shear keys in "ordinary" bridges limit the capacity of shear keys to be smaller than $30 \%$ of the dead load vertical reaction at the abutment and $75 \%$ of the total lateral pile capacity (CALTRANS 2006).

Recent experiments conducted on the seismic performance of shear keys designed according to current CALTRANS design criteria indicate that "actual" breakoff strength of shear keys may be significantly higher than the design value (Bozorgzadeh et al. 2003, 2006; Megally et al. 2001). While shear keys with such

${ }^{1}$ Professor, Dept. of Civil \& Environmental Engineering, California Polytechnic State Univ., San Luis Obispo, CA 93407-0353 (corresponding author). E-mail: rgoel@calpoly.edu

${ }^{2}$ Johnson Professor, Dept. of Civil \& Environmental Engineering, Univ. of California, Berkeley, CA 94720. E-mail: chopra@ce.berkeley. edu higher breakoff strengths may lead to damage in abutment walls and piles, for bridges subjected to spatially uniform ground motion they tend to limit the deformation demands in other critical locations, such as column drifts and displacement of the deck at the abutments. Therefore, shear keys are generally ignored when idealizing a bridge, because it is assumed that it provides upper bound estimates of the seismic displacement demands. Given that, it is not clear if ignoring shear keys will always provide upper bound estimates of these demands for bridges that cross fault-rupture zones and hence be subjected to spatially varying ground motion.

The objective of this investigation is to develop an improved understanding of the role that shear keys play in affecting the seismic response of "ordinary" bridges crossing fault-rupture zones. In particular, the seismic response of bridges subjected to spatially uniform ground motion as well as bridges subjected to spatially varying ground motion expected in fault-rupture zones are examined with different shear-key conditions. Results show that although the traditional practice of ignoring shear keys provides a conservative estimate of seismic demands in bridges subjected to spatially uniform ground motion, such a practice may lead to underestimation of some seismic demand quantities for bridges crossing fault-rupture zones. It is further demonstrated that seismic demands for bridges crossing fault-rupture zones are generally bounded by the demands determined by analyzing the bridge for two cases: (1) a bridge with elastic shear keys; and (2) a bridge without shear keys.

The scope of this research investigation was limited to "ordinary" bridges in California, whose design is governed by the CALTRANS SDC (CALTRANS 2006). "Ordinary" bridges are defined as normal weight concrete bridges with span lengths less than $90 \mathrm{~m}$, supported on the substructure by pin/rigid connections or conventional bearings. The bent caps of "ordinary" bridges terminate inside the exterior girders, and their foundations consist of spread footing, piles, or pile shafts, with underlying soil that is not susceptible to liquefaction, lateral spreading, or scour. 


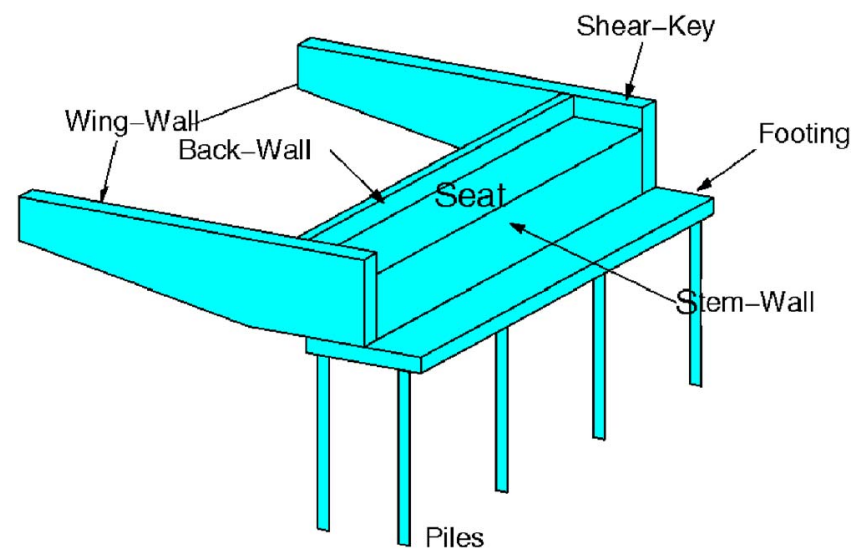

Fig. 1. Typical abutment details

\section{Structural System and Modeling}

The structural systems considered in this investigation are as follows: (1) a three-span symmetric bridge [Fig. 2(a)]; (2) a three-span unsymmetric bridge [Fig. 2(b)]; (3) a four-span symmetric bridge [Fig. 2(c)]; and (4) a four-span unsymmetric bridge [Fig. 2(d)]. These bridges, with no skew, are supported on abutments at the two ends and intermediate single-column bents. The span lengths and bent heights are shown in Fig. 2. The bases of columns in the bents are fixed (restrained in all six degrees of freedom). The deck, a multicell box girder, is expected to accommodate two traffic lanes (Fig. 3). The columns selected are $1.5 \mathrm{~m}$ diameter circular sections, with helical transverse (or hoop) steel and longitudinal steel arranged at its periphery (Fig. 4). The area of longitudinal steel selected is $2 \%$ of the gross columns area, and hoop steel selected is $1 \%$ of the column volume to represent well confined columns; such heavy reinforcement is appropriate for columns in bridges crossing fault-rupture zones. Although not reported here for reasons of brevity, a parametric analysis for a different ratio of longitudinal and hoop steel indicated that the observations and conclusions presented in this paper are relatively insensitive to these parameters.

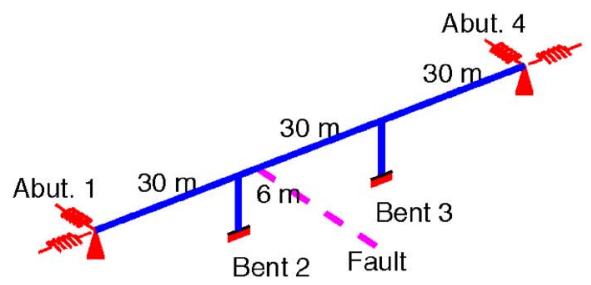

(a)

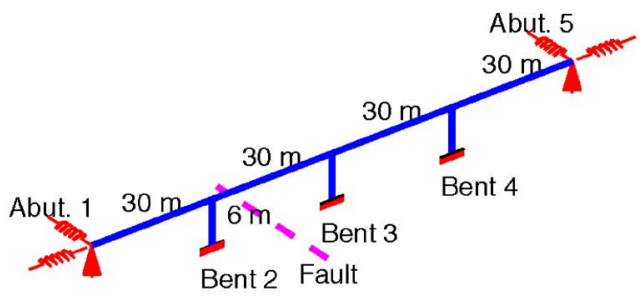

(c)

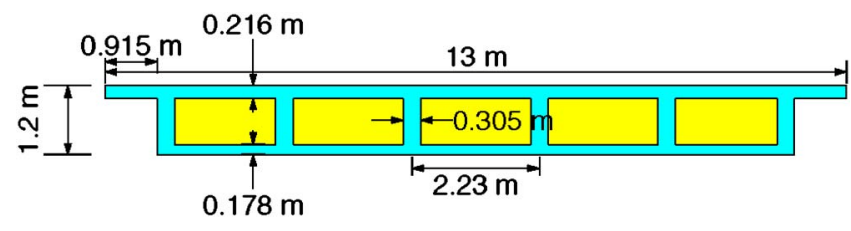

Fig. 3. Cross section of bridge deck

The structural systems considered in this investigation do not necessarily represent "actual" bridges. They were selected in consultation with CALTRANS engineers to investigate the bridge behavior for varying parametric conditions: the number of spans (three-span versus four-span bridges) and asymmetry in bridge geometry (symmetric bridges versus asymmetric bridges). It is assumed that the conclusions gleaned from analyzing the seismic behavior of these "ordinary" bridges will be generally applicable for most "actual" bridges.

The selected bridge systems were analyzed using the structural analysis software Open System for Earthquakes Engineering Simulation (OpenSees) (McKenna and Fenves 2001), whereby the girder was modeled as linearly elastic beam-column elements. In order to capture the distribution of mass along the length of the deck, five elements per span were used. Consistent with CALTRANS' recommendations, the gross values for moment of inertia and polar moment of inertia were used for a prestressed multicell box deck girder. The columns were modeled as nonlinear beam-column elements, whose specified cross-sectional properties were based on a fiber section. Details on the modeling are available in McKenna and Fenves (2001).

The abutments were modeled as springs in the longitudinal and transverse directions. The longitudinal springs were elasticperfectly plastic springs with a gap to account for the gap between end of the deck and the abutment back wall, which is provided to accommodate thermal movement. The stiffness, $K_{L}$, and strength, $F_{y L}$, of the longitudinal springs were computed according to CALTRANS recommendations (CALTRANS 2006, Section 7.8.1)

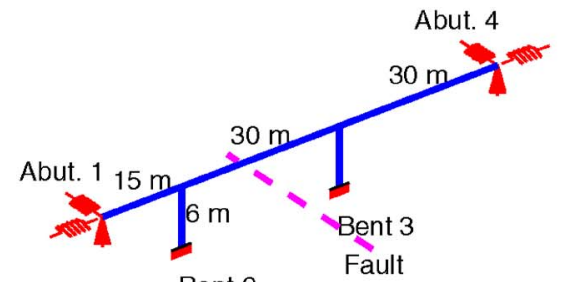

(b)

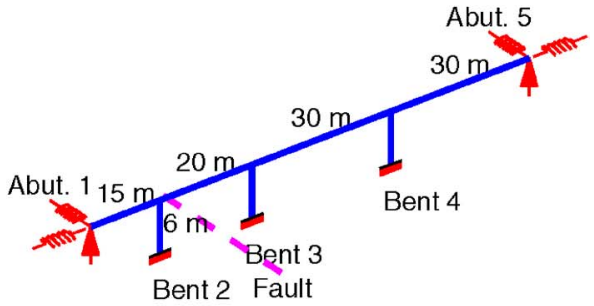

(d)

Fig. 2. Bridges considered: (a) three-span symmetric bridge; (b) three-span unsymmetric bridge; (c) four-span symmetric bridge; and (d) four-span unsymmetric bridge 


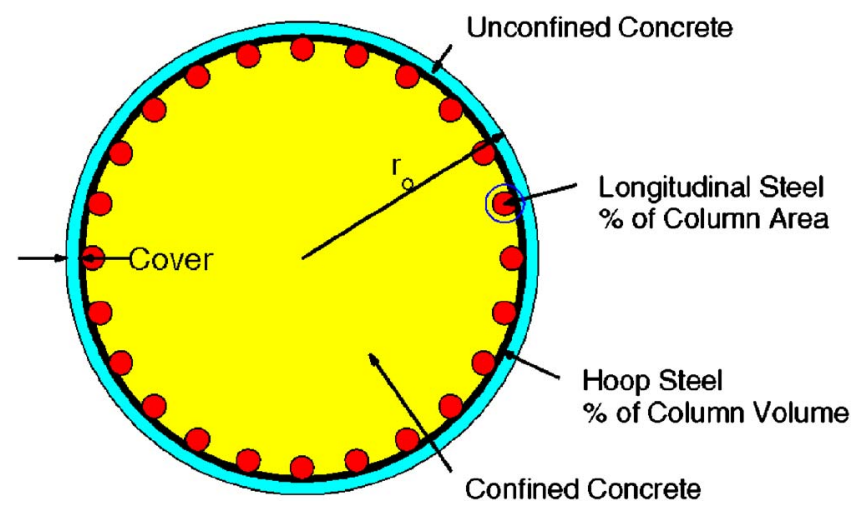

Fig. 4. Column cross section

$$
\begin{gathered}
K_{L}=11500 W \frac{H}{1.7} \mathrm{kN} / \mathrm{m} \\
F_{y L}=239 A \frac{H}{1.7} \mathrm{kN}
\end{gathered}
$$

where $W$ and $H=$ width and height of the back wall (m); and $A=$ area of back wall $\left(\mathrm{m}^{2}\right)$ for a seat-type abutment.

The transverse springs model the contributions of the foundation system as well as the shear keys. While CALTRANS provided recommendations on the stiffness of transverse springs that model the pile-supported foundation (to be discussed later in this paper), no clear guidelines were given to model shear keys that exhibit highly nonlinear behavior with brittle failure. Experiments conducted at the University of California at San Diego (UCSD) (Bozorgzadeh et al. 2003, 2006; Megally et al. 2001) have established force-deformation behavior of shear keys with different detailing. Although details to improve the shear key behavior have been proposed, including various mechanisms to establish failure load of shear keys, no consensus has yet been reached on force-deformation (or hysteretic) behavior of shear keys.

This investigation utilized a simple trilinear force-deformation model (Fig. 5) based on the experiment results obtained from the UCSD research on shear keys (Megally et al. 2001). The reference (or starting) strength of the shear key at each abutment was assumed to be equal to $30 \%$ of the dead load vertical reaction at

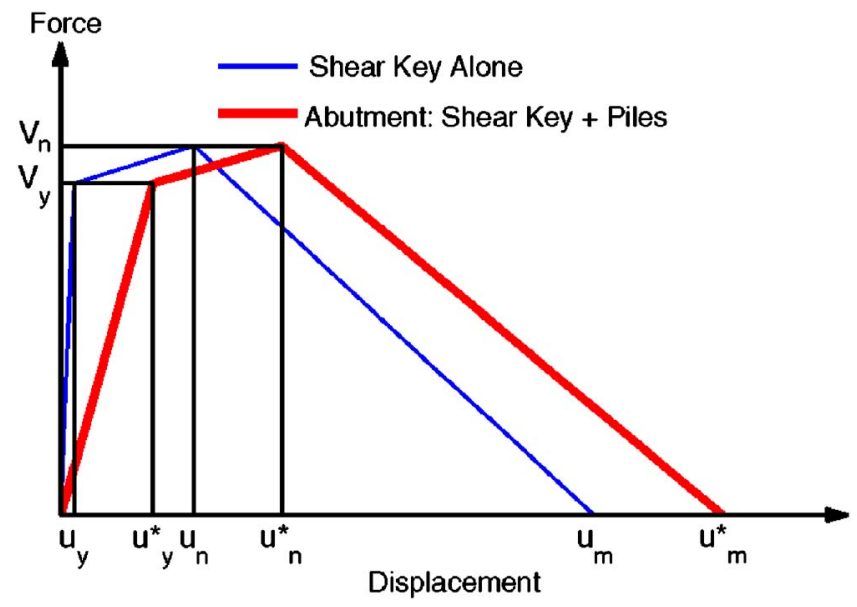

Fig. 5. Force-deformation behavior of shear keys and abutment
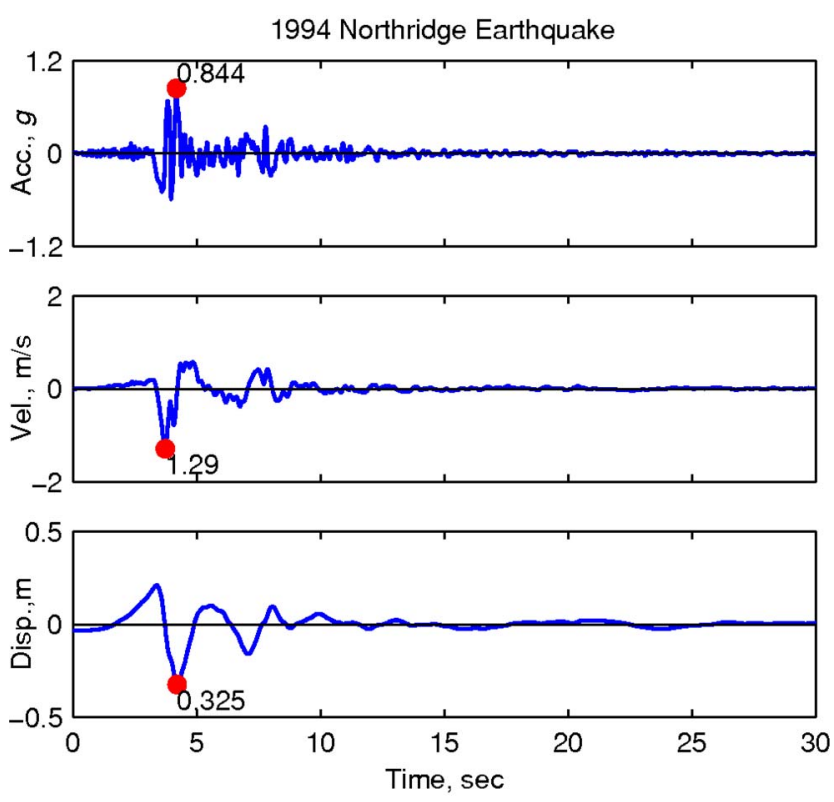

Fig. 6. Spatially uniform ground motion considered

that abutment. Details of the development of the forcedeformation behavior of the shear key are presented in the Appendix.

The tests conducted at UCSD did not include the flexible piles that support the abutment. Pile flexibility is included in obtaining the abutment force-deformation behavior by assuming that the shear key and the piles act as springs in series. The modified force-deformation relationship of the abutment with shear-keypile system is shown in Fig. 5; a stiffness of 7,000 kN/m per pile was selected per CALTRANS recommendations (CALTRANS 2006), assuming a total of 12 piles per abutment. Note that including pile flexibility makes displacements $u_{y}^{*}, u_{n}^{*}$, and $u_{m}^{*}$ larger than $u_{y}, u_{n}$, and $u_{m}$, but it does not affect the forces $V_{y}$ and $V_{n}$.

It is useful to emphasize that nonlinearity in the structural systems was restricted to the columns and the shear keys (where appropriate). The girder was assumed to remain linear elastic. These assumptions were based on consultations with CALTRANS engineers, who indicated nonlinearity (or hinging) in the girder to be unacceptable. Furthermore, soil-structure interaction at the two abutments was not explicitly considered because the scope of this investigation is limited to "ordinary" bridges, and such a detailed analysis may not be necessary.

\section{Ground Motions}

This investigation examined the seismic demands for selected structural systems subjected to two types of ground motions: (1) spatially uniform ground motion resulting from near-field or farfield earthquakes; and (2) spatially varying ground motion resulting from rupture of a fault.

For this study, the ground motion recorded during the 1994 Northridge earthquake at the Sylmar County Hospital parking lot in the north-south direction (Fig. 6) was selected as the spatially uniform ground motion, with a peak ground acceleration, velocity, and displacement of $0.844 \mathrm{~g}, 1.29 \mathrm{~m} / \mathrm{s}$, and $0.325 \mathrm{~m}$, respectively. This motion represents strong shaking that may occur in regions where fault rupture does not extend all the way to the 


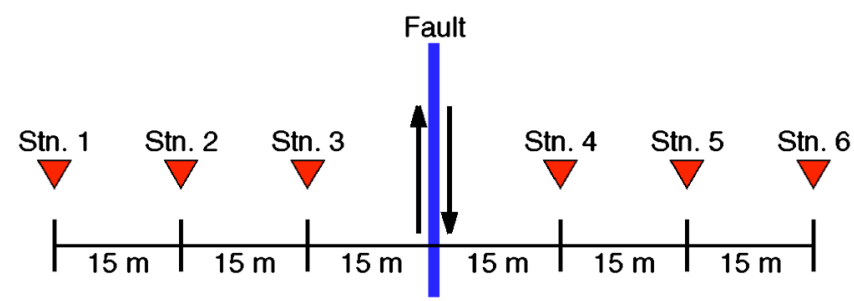

Fig. 7. Location of stations across fault where spatially varying ground motions were simulated

ground surface. This motion is applied as uniform excitation to all supports of the selected bridge in the transverse direction.

To date, ground motions have never been recorded in close proximity to the causative fault. Because part of the scope of this study demanded that the second excitation considered be a spatially varying ground motion at the supports of a bridge crossing a fault rupture zone, ground motions were numerically simulated at stations spaced $15 \mathrm{~m}$ apart from the fault (Fig. 7) for a magnitude 6.5 earthquake using an elastic finite-difference code. The simulation method utilized a fourth-order accurate staggered-grid elastic finite-difference code, ELAS3D, developed at Lawrence Livermore National Laboratory (Larsen and Schultz 1995). Stress-free boundary conditions were used to model the free surface, and absorbing boundary conditions (Clayton and Engquist 1977) were used to damp artificial reflections from the grid boundary. Further details of the procedure to generate ground motions are available elsewhere (Dreger et al. 2007).

The fault parallel component of ground acceleration, velocity, and displacement at Stations 1-6 resulting from this simulation are shown in Fig. 8. Note that only the fault parallel component of the ground motion in the fault-rupture zone is considered in this investigation. Because shear keys are engaged only by the fault parallel motion in selected bridges, which are perpendicular to the fault, it is expected that no coupling between response of the bridge due to fault normal, fault parallel, and vertical motions will occur.
The ground motions across the fault-rupture zone (Fig. 8) exhibit several characteristics that are typically not found in most near-fault and far-fault motions where the fault does not rupture all the way to the ground surface. First, the motions in the faultrupture zone exhibit a permanent ground offset after the ground has stopped shaking due to permanent displacement of the ground in opposite directions on two sides of the fault; this is typically referred to as the "fling" effect. The total offset between two sides of the fault after the selected earthquake is $0.70 \mathrm{~m}$ (Fig. 8). Second, fault-parallel motions are essentially antisymmetric about the fault plane, i.e., fault-parallel motions on two sides of the fault plane are almost equal in magnitude but opposite in algebraic sign. Third, spatial variation in fault-parallel motions on either side of the fault appear to be minimal across the closely spaced supports typical of "ordinary" bridges. For example, peak accelerations are $0.19,0.2$, and $0.2 g$, and the peak velocities are 0.65 , 0.66 , and $0.67 \mathrm{~m} / \mathrm{s}$ at Stations 1, 2, and 3, respectively (Fig. 8).

For the selected location of the fault, the simulated motions were applied at all supports of the three-span bridges: motions at Stations $1,3,4$, and 6 were applied to abutment 1 , bent 2 , bent 3 , and abutment 4 , respectively, of the three-span symmetric bridge [Fig. 2(a)]; and motions at Stations 2, 3, 4, and 6 were applied to abutment 1 , bent 2 , bent 3 , and abutment 4 , respectively, of the three-span unsymmetric bridge [Fig. 2(b)]. The motions were available only at abutment 1 , bent 2 , bent 3 , and bent 4 (Stations $1,3,4$, and 6) of the four-span symmetric bridge, and at bent 3 and bent 4 (Stations 4 and 6) of the four-span unsymmetric bridge. Because spatial variation among motions on the same side of the fault is minimal, motions at abutment 5 of the four-span symmetric bridge were assumed to be identical to those at Station 6 ; and motions at abutment 1 , bent 2 , and abutment 5 of the four-span unsymmetric bridge were assumed to be those at Stations 2,3 , and 6 , respectively.

\section{Analytical Procedure and Response Quantities}

Using the OpenSees computer program (McKenna and Fenves 2001), nonlinear response history analysis (RHA) was used to
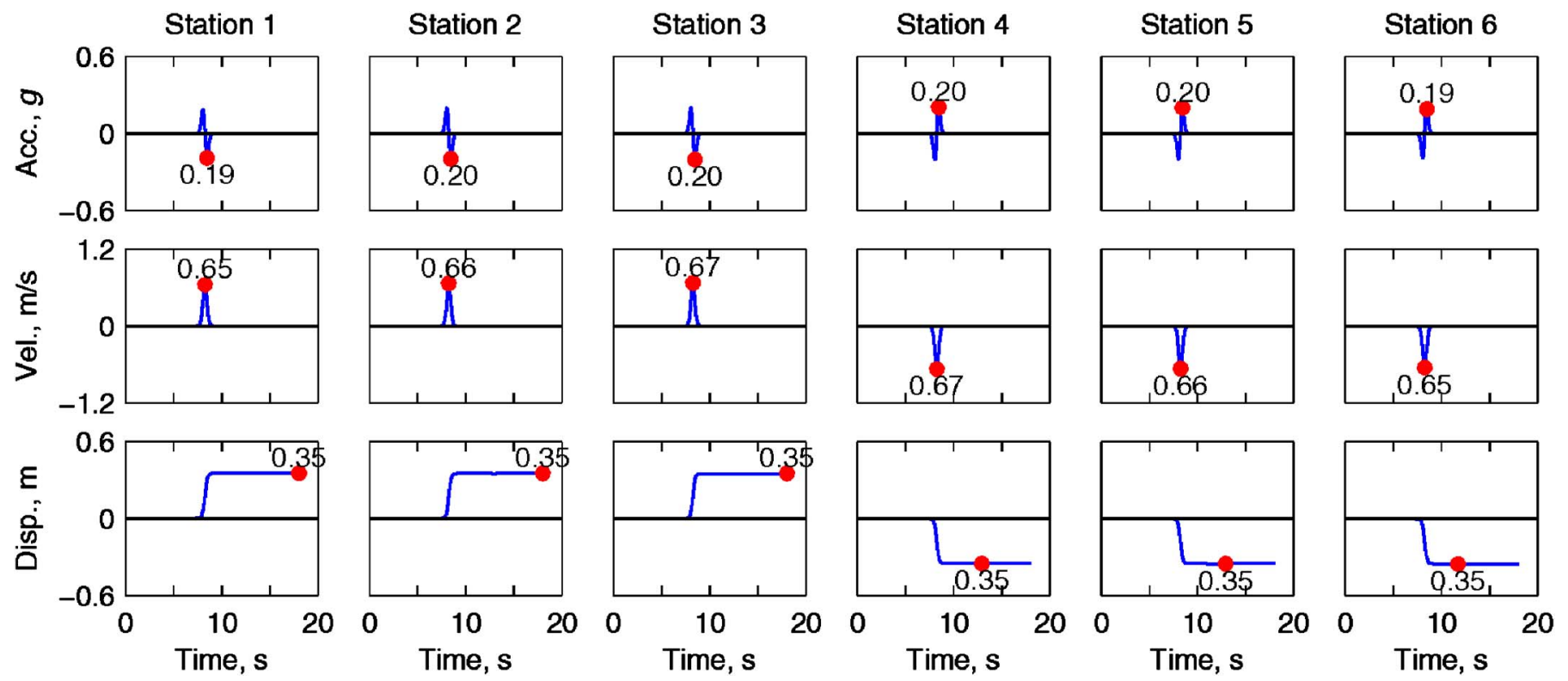

Fig. 8. Spatially varying ground motion in fault-parallel direction simulated in fault-rupture zone during magnitude 6.5 earthquake on strike-slip fault 

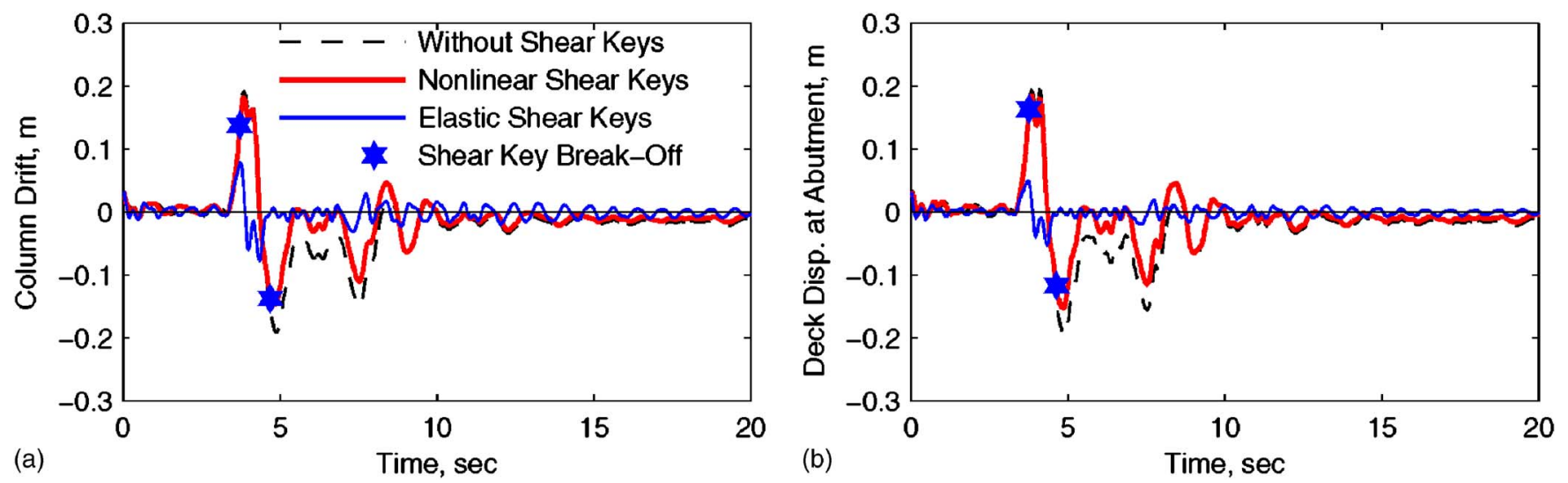

Fig. 9. Response history for three-span symmetric bridge subjected to spatially uniform ground motion: (a) column drift in bent 2; (b) deck displacement at abutment 1

compute the response of selected bridges subjected to spatially uniform as well as spatially varying ground motion, whereby fault-parallel ground displacements were directly imposed on the support degrees of freedom of the system. Identical ground displacements were imposed at all supports of bridges subjected to spatially uniform ground motion, whereas different ground displacements were applied to various supports of bridges crossing fault-rupture zones.

The inherent damping for all selected bridges was modeled with Rayleigh's damping (Chopra 2007): $\mathbf{c}=a_{0} \mathbf{m}+a_{1} \mathbf{k}$, where $\mathbf{m}=$ mass matrix of the system; $\mathbf{k}=$ initial elastic stiffness matrix of the system; and $a_{0}$ and $a_{1}=$ mass- and stiffness-proportionality coefficients. In order to maintain damping ratio at about $5 \%$ in the most significant modes of the selected systems, values of $a_{0}$ and $a_{1}$ were selected to be 0.4134 and 0.004837 , respectively.

Response quantities of interest in this investigation are the column drift and deck displacement at the abutment. Defined as the displacement at the top of the column relative to its base displacement, the column drift indicates the deformation demand for the column. Defined as the displacement of the deck at the abutment relative to the displacement of the abutment, the deck displacement at the abutment is useful for estimating the seat widths needed to prevent unseating of the deck from the abutment. Because shear keys are expected to influence bridge response primarily in the transverse direction, only transverse column drifts and deck displacements at abutments were considered in this investigation. The response quantities presented are the largest column drift and the largest deck displacement at the abutment; the column and the abutment where the largest response occurs are identified later in each figure. Note that strength demands, such as column bending moment or shear force, were not part of the scope of this investigation.

\section{Shear-Key Cases and Parameters}

For shear keys at the abutment three cases were considered. In the first case, shear keys do not engage during the design ground shaking, which is an appropriate model if shear keys are designed and constructed to break off soon after onset of the design ground shaking. For this case, denoted as the bridge without shear keys, no springs were specified in the transverse direction at the abutment. In the second case, shear keys remain elastic and do not break off during the ground shaking, which is an appropriate model if shear keys are much stronger than the design breakoff strength. For this case, denoted as the bridge with elastic shear keys, elastic springs with stiffness equal to the initial abutment stiffness (see Fig. 5) were specified in the transverse direction. The third case considered nonlinear behavior of shear keys. For this case, denoted as the bridge with nonlinear shear keys, shear keys were modeled as nonlinear springs in the transverse direction with force-deformation behavior specified by the trilinear relationship presented in Fig. 5. In the second and third cases, shear keys were assumed to provide transverse restraint in both positive and negative direction of the deck displacement, with identical force-deformation behavior in the two directions. Note that bridge columns were permitted to respond beyond the linear elastic range for all shear-key conditions.

In addition to the three shear-key cases defined above, also investigated was how seismic demands for the bridge vary depending on the strength of the shear keys. For this purpose, the normalized shear key strength was varied between 0 and 4 , where the value of one denotes a shear key with the strength equal to $30 \%$ of the dead load reaction at the abutment. As the normalized shear-key strength approaches zero, the bridge behavior approaches that of a bridge without shear keys. For values of normalized shear-key strength much larger than 1, the bridge behavior approaches that of a bridge with elastic shear keys.

\section{Seismic Response of Bridges with Shear Keys}

This section investigates the influence of shear keys on the seismic response of the three-span symmetric bridge subjected to two types of excitations: (1) spatially uniform ground motion; and (2) spatially varying ground motion characteristic of fault-rupture zones. For each type of ground motion, the response histories of the bridge with three shear-key conditions are examined firstwithout shear keys, nonlinear shear keys, and elastic shear keysfollowed by the variation of peak values of seismic demands with shear-key strength.

\section{Spatially Uniform Ground Motion}

Fig. 9 shows the time variation of column drift and deck displacement at the abutment of the three-span symmetric bridge for the three shear-key cases subjected to spatially uniform ground motion. These results show that the smallest of both responses occurs for the bridge with elastic shear keys; the shear keys continue to provide transverse restraint throughout the ground shaking, lead- 

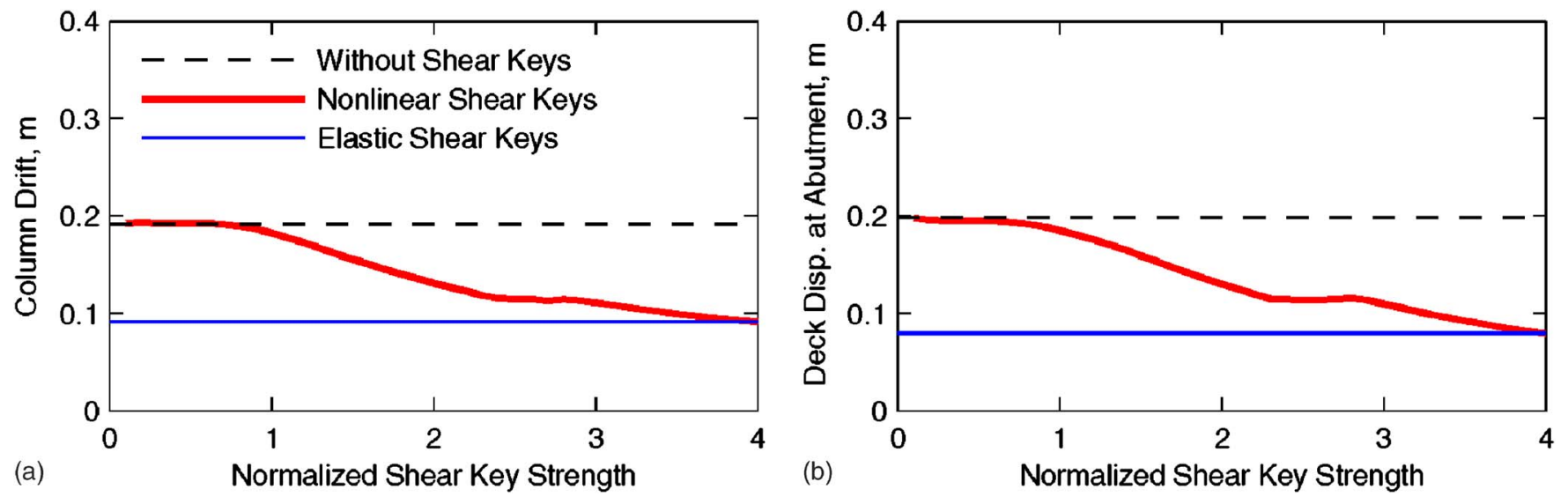

Fig. 10. Variation of peak responses with normalized shear key strength for three-span symmetric bridge subjected to spatially uniform ground motion: (a) column drift in bent 2; (b) deck displacement at abutment 1

ing to a stiffer structural system. In contrast, the largest of both responses occurs for the bridge without shear keys, where there isn't any transverse restraint. The responses in the bridge with nonlinear shear keys, whereby shear keys initially provide transverse restraint but break off if deformed beyond a certain limit, are initially identical to that of the bridge with elastic shear keys. After shear keys break off on both sides of the deck, a bridge with nonlinear shear keys oscillates in a manner essentially similar to the bridge without shear keys, but about a different permanent drift.

Fig. 10 shows how the peak column drift and peak deck displacement at an abutment vary with normalized strength of the nonlinear shear key in a bridge with nonlinear shear keys. Also included for reference are the peak demands for the bridge with elastic shear keys and the bridge without shear keys; for obvious reasons, these demands are independent of the normalized shearkey strength. As expected, the results presented show that the seismic demands for a bridge with nonlinear shear keys of very low strength approach those of the bridge without shear keys and the seismic demands for a bridge with very strong shear keys approach those of the bridge with elastic shear keys. For intermediate values of normalized shear key strength, seismic demands for the bridge with nonlinear shear keys fall between or are bounded by the demand values for the bridge without shear keys and bridge with elastic shear keys.

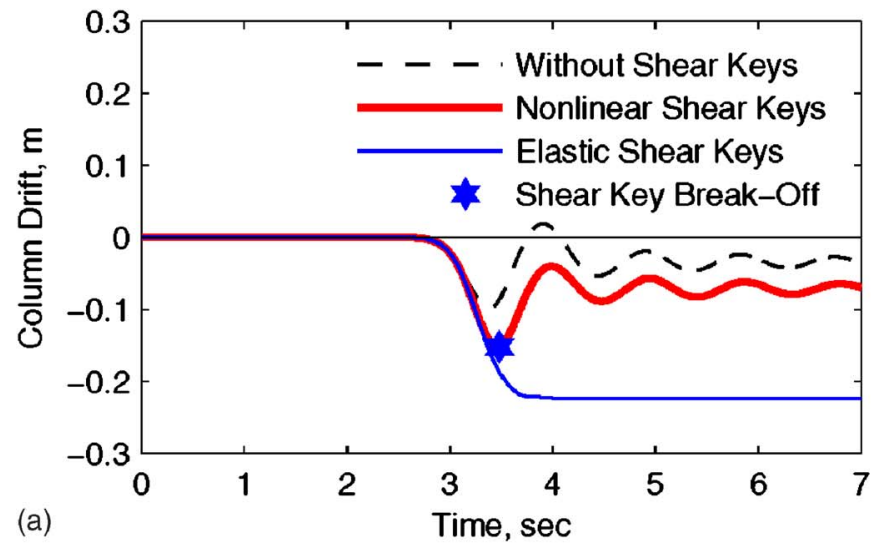

\section{Spatially Varying Ground Motion in Fault-Rupture Zone}

Fig. 11 shows the time variation of column drift and deck displacement at an abutment of the three-span symmetric bridge for the three shear-key cases subjected to spatially varying ground motion expected in a fault-rupture zone (Fig. 8). Comparing the results for the three cases, the smallest column drift occurred for the bridge without shear keys, whereas the smallest deck displacement occurred for the bridge with elastic shear keys. In contrast, among the three cases, the largest column drift occurred for the bridge with elastic shear keys and the largest deck displacement occurred for the bridge without shear keys. Thus seismic response trends for a bridge crossing a fault-rupture zone differ from that of this bridge subjected to spatially uniform ground motion. In the first case, among the three shear key cases, the largest response may occur either in the bridge without shear keys (e.g., deck displacement at the abutment) or in the bridge with elastic shear keys (e.g., column drift) (see Fig. 11), whereas in the second case, the seismic demand is largest for the bridge without shear keys (see Fig. 9).

Fig. 11 demonstrates that, as observed previously for spatially uniform ground motion, the response of the bridge (with nonlinear shear keys) crossing a fault-rupture zone is initially identical to that of the bridge with elastic shear keys. After breakoff of shear keys, the bridge oscillated in a manner similar to the bridge

Fig. 11. Response histories for three-span bridge subjected to spatially varying ground motion: (a) column drift in bent 2; (b) deck displacement

at abutment 1

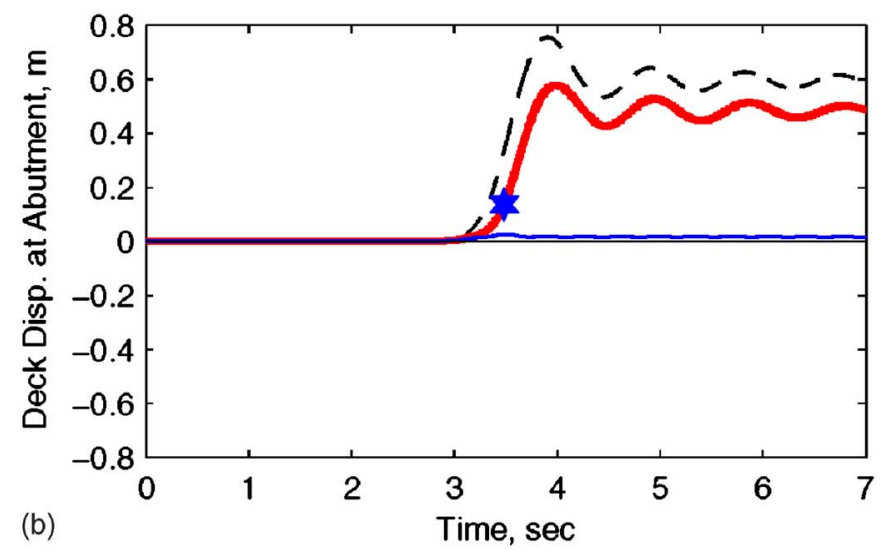



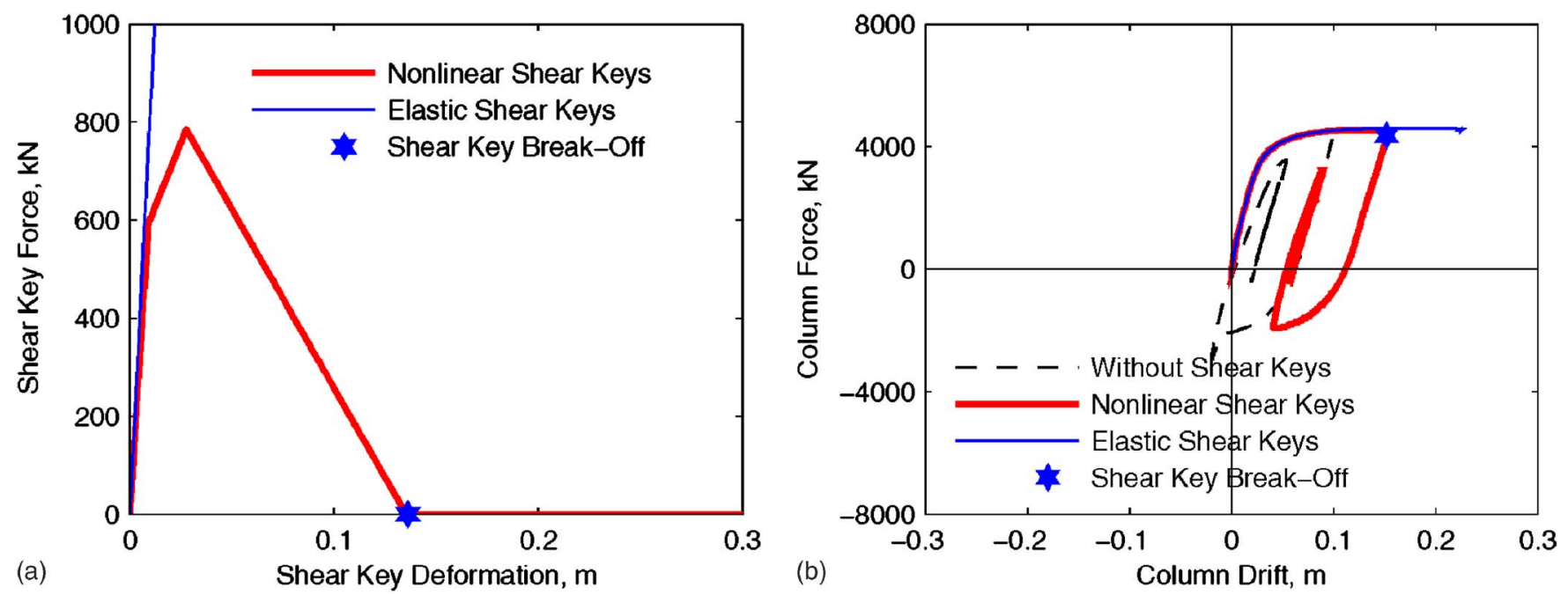

Fig. 12. Force-deformation relations for three-span symmetric bridge subjected to spatially varying ground motion: (a) shear-key at abutment 1 ; (b) column in bent 2

without shear keys, but about a different permanent displacement. The different permanent displacement [both column drift and deck displacement at the abutment (Fig. 11) in the bridge with nonlinear shear keys after breakoff of shear keys] occurred due to different permanent offset that occurs in the bridge columns (as will be demonstrated next). Note that the strength and stiffness of the bridge after shear-key breakoff is entirely due to the bridge columns.

Fig. 12 shows the force-deformation relations for a shear key and a column in a bridge crossing a fault-rupture zone. As expected, the shear keys exhibited a linearly elastic forcedeformation relationship for the bridge with elastic shear keys, and a selected trilinear force-deformation relationship for the bridge with nonlinear shear keys [Fig. 12(a)]. In the latter case, the shear key ceased to provide any resistance at a deformation of about $0.13 \mathrm{~m}$, denoted as the shear key breakoff point [Fig. 12(a)]. The shear key is loaded only in one direction (without any unloading or reloading) because the ground displacement, which resembles a step function with finite rise time (Fig. 8), deformed the shear key only in one direction. The column experienced significant inelastic action for all three shear-key conditions [Fig. 12(b)], with the extent of inelastic action depending on the condition of the shear keys. The column deformed farthest into the inelastic range in the bridge with elastic shear keys and the least in the bridge without shear keys. The column experienced permanent drift for all three shear-key conditions, which was largest in the bridge with elastic shear keys and smallest in the bridge without shear keys.

Fig. 13 shows how peak column drift and peak deck displacement at the abutment varied with normalized strength of nonlinear shear keys, along with the peak demands for the bridge with elastic shear keys and for the bridge without shear keys. As in the case of spatially uniform ground motion (Fig. 10), even for a bridge crossing a fault-rupture zone, the seismic demands in the bridge with elastic shear keys and without shear keys provided upper and lower bounds for seismic demands on a bridge with nonlinear shear keys (Fig. 13). The bridge without shear keys provides an upper bound for deck displacement at the abutment and the bridge with elastic shear keys provided a lower bound [Fig. 13(b)]. This trend reversed, however, for column drift for which the bridge with elastic shear keys provided an upper bound and the bridge without shear keys led to a lower bound [Fig. 13(a)].

Fig. 13 also shows that seismic response of bridges crossing
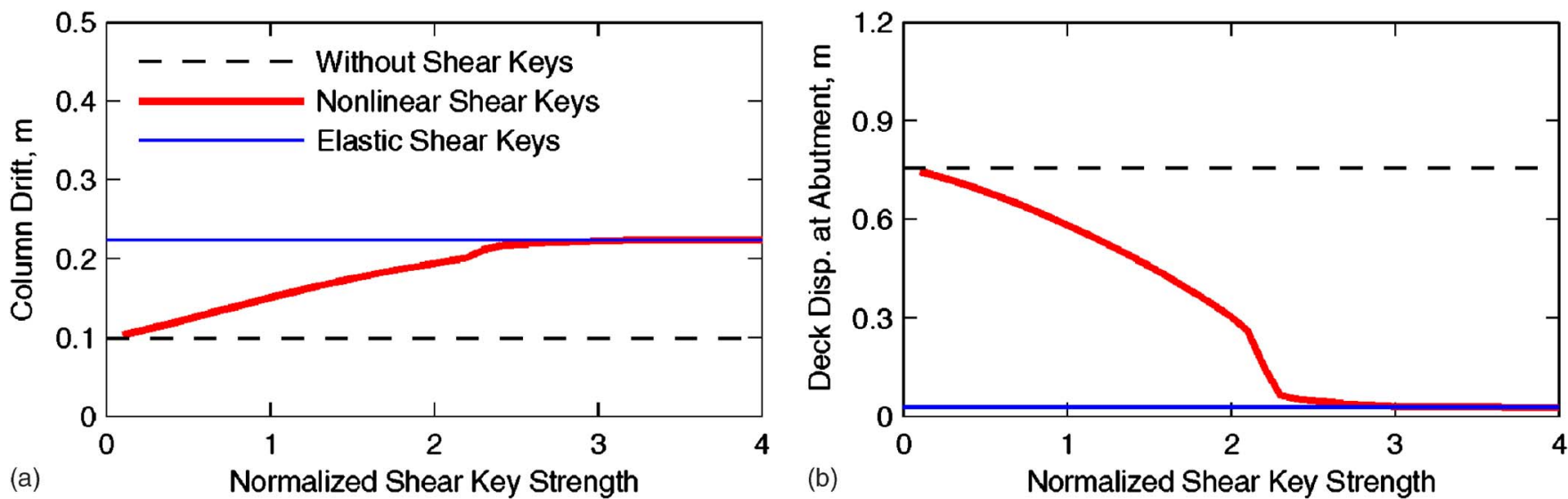

Fig. 13. Variation of peak responses with normalized shear key strength for three-span symmetric bridge subjected to spatially varying ground motion: (a) column drift in bent 2; (b) deck displacement at abutment 1 

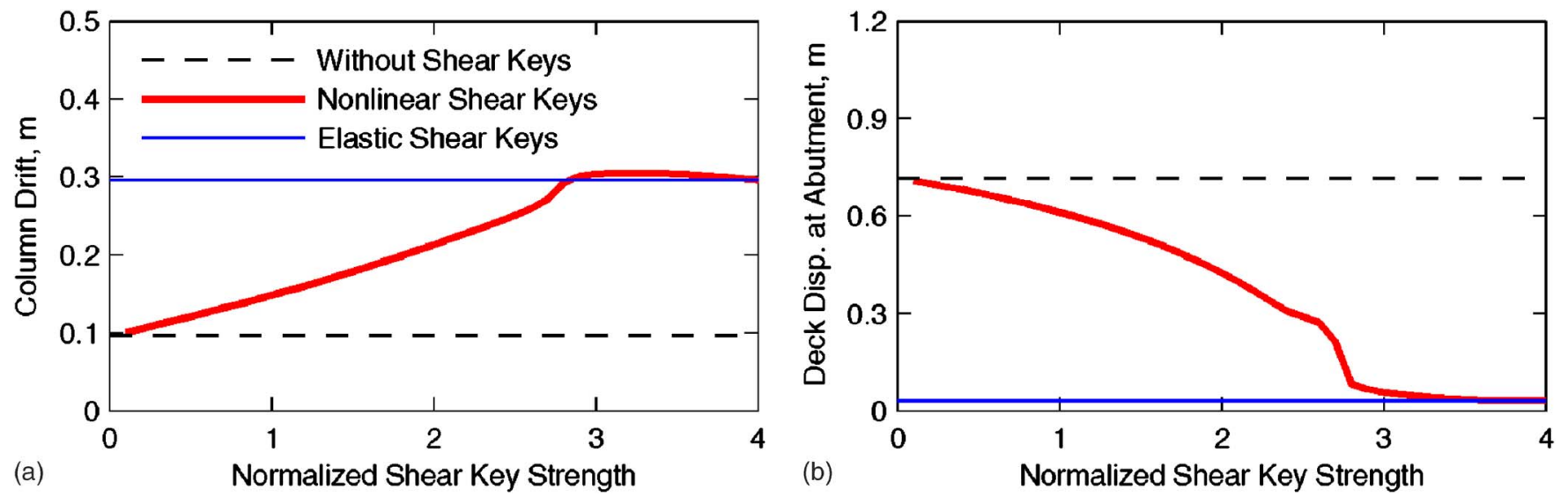

Fig. 14. Variation of peak responses with normalized shear key strength for three-span unsymmetric bridge subjected to spatially varying ground motion: (a) column drift in bent 3; (b) deck displacement at abutment 4

fault rupture zones may be very sensitive to the strength of shear keys. For example, column drift in a bridge with very strong shear keys (normalized shear key strength greater than two) is more than twice that in a bridge with very weak shear keys (normalized shear key strength approaching zero) [Fig. 13(a)]. The deck displacement at abutment in a bridge with very strong shear keys is almost negligible but becomes very large in a bridge with very weak shear keys [Fig. 13(b)].

\section{Upper Bounds of Seismic Demands}

Design practice generally requires an upper bound of seismic demand for various parametric conditions. Therefore, it is useful to reexamine the results of Figs. 10 and 13 to establish which of the three shear-key conditions provides an upper bound of seismic demand.

The results of Fig. 10 for a three-span symmetric bridge subjected to spatially uniform ground motions show that the seismic demands in the bridge without shear keys provide an upper bound of both seismic demands (column drift and deck displacement at the abutment) on the bridge with nonlinear shear keys. This implies that the current practice of ignoring transverse restraint provided by shear keys in estimating seismic displacement demands of bridges is valid for spatially uniform ground motion.
The results of Fig. 13 for a three-span symmetric bridge subjected to spatially varying ground motion in a fault-rupture zone demonstrate that ignoring transverse restraint provided by shear keys, i.e., by analyzing a bridge without shear keys, may not always provide an upper bound value for all seismic demand quantities. For the selected bridge, while ignoring shear keys provides an upper bound for deck displacement at the abutment [Fig. 13(b)], the column drift is underestimated [Fig. 13(a)], however, including elastic shear keys provides an upper bound for column drift. Therefore, a bridge should be analyzed for both shear-key cases (without shear keys and with elastic shear keys) to establish upper bounds for all seismic demands in the bridge. For the bridge subjected to spatially varying ground motion expected in a fault-rupture zone, the traditional practice of ignoring transverse restraint provided by shear keys may lead to underestimation of some seismic demands.

The generality of the preceding conclusion is further supported by an examination of the peak seismic demands in three other bridges: a three-span unsymmetric bridge, a four-span symmetric bridge, and a four-span unsymmetric bridge. The results of Figs. 14-16 permit the following observations: (1) each of the two responses (the peak deck displacement at an abutment and peak column drift) of the three other bridges are generally bounded by the seismic demand estimates for two shear key
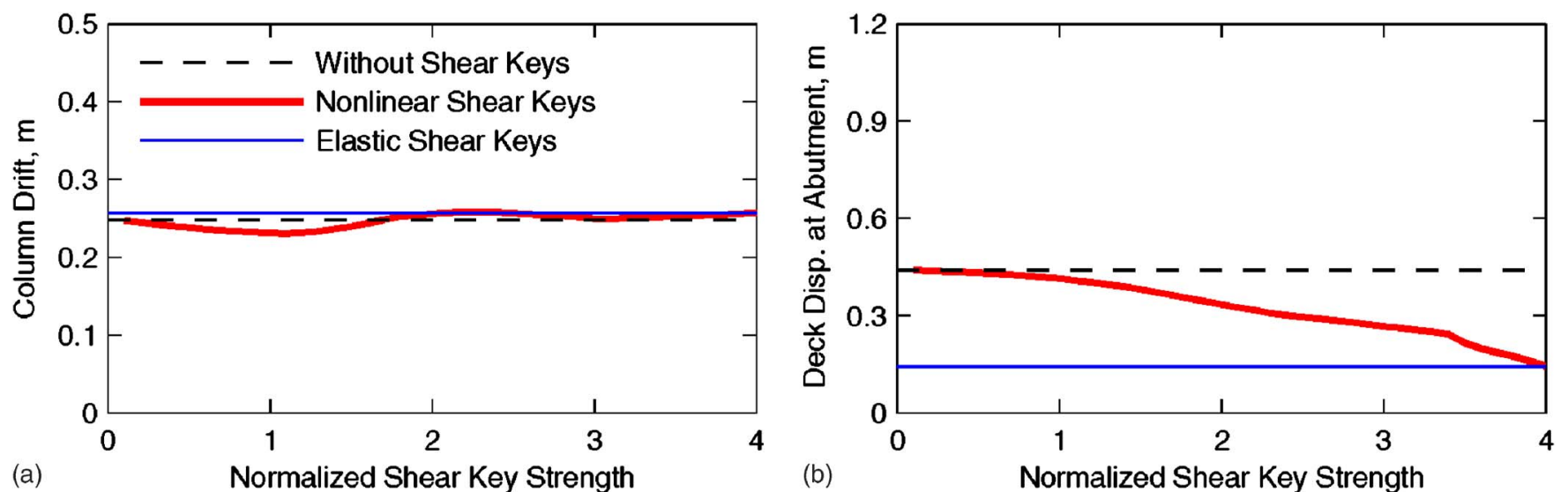

Fig. 15. Variation of peak responses with normalized shear key strength for four-span symmetric bridge subjected to spatially varying ground motion: (a) column drift in bent 3; (b) deck displacement at abutment 1 

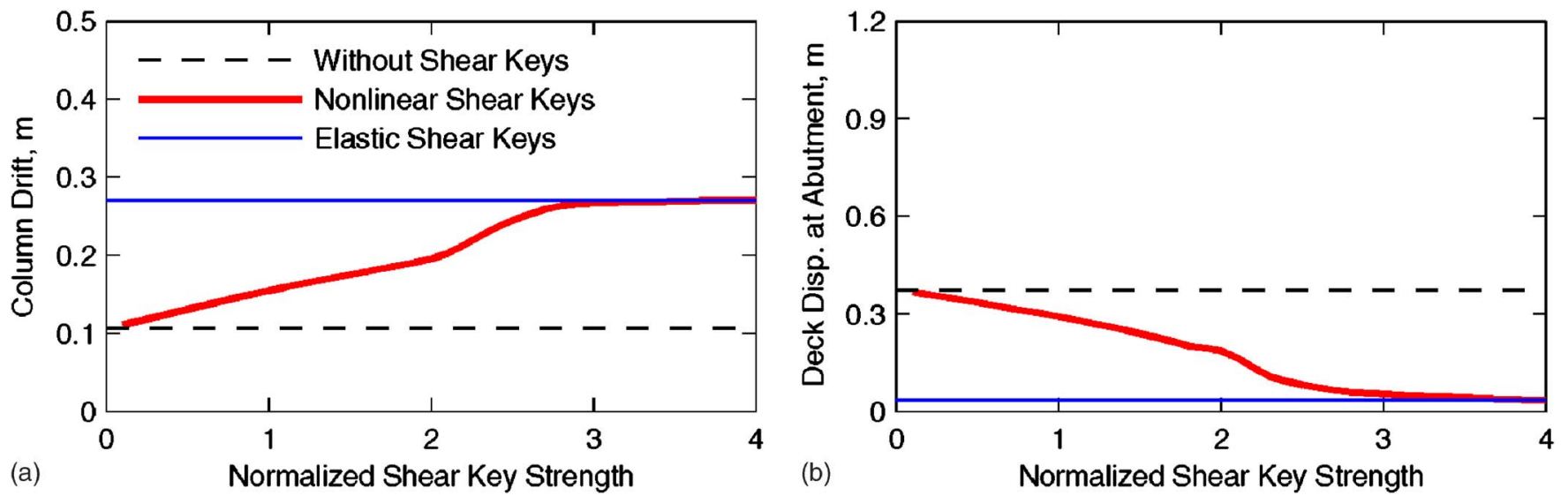

Fig. 16. Variation of peak responses with normalized shear key strength for four-span unsymmetric bridge subjected to spatially varying ground motion: (a) column drift in bent 4; (b) deck displacement at abutment 5

cases: without shear keys and with elastic shear keys; (2) the bridge without shear keys provides an upper bound for deck displacement at an abutment; and (3) the bridge with elastic shear keys generally provides an upper bound for column drift. The first and second observations are generally valid, but exceptions at a few values of shear-key strength are noted in Figs. 14(a) and 15(a). Note, these deviations are minor, therefore a design value for the column drift in a bridge with nonlinear shear keys can be estimated to a useful degree of accuracy by analyzing a bridge with elastic shear keys.

The occurrence of larger deck displacement at an abutment for a bridge without shear keys and larger column drift in a bridge with elastic shear keys can be explained based on observations on the deflected shape of a bridge to static application of support displacements that are expected during fault rupture. For this purpose, consider the deflected shape of the three-span symmetric bridge subjected to equal but opposite motions on two sides of the fault that ruptures between bents 2 and 3 (Fig. 17). The bridge without shear keys rotates essentially as a rigid body about a vertical axis [Fig. 17(a)]. For such a deflected shape, the displacement of the girder at its two edges, i.e., at the two abutments, are the largest; however, drift in the columns, i.e., displacement of a column at the top relative to its bottom, is essentially zero. Although the bridge with elastic shear keys exhibits rotational displacements about the vertical axis, it no longer rotates as a rigid body about the vertical axis but involves deformation of the girder [Fig. 17(b)]. Because of stiffness of the shear keys, the displacement at the two edges of the girder and hence deck displacements at the two abutments are smaller compared to the bridge without shear keys. The column drifts, however, are larger in the bridge with elastic shear keys. This occurs because the

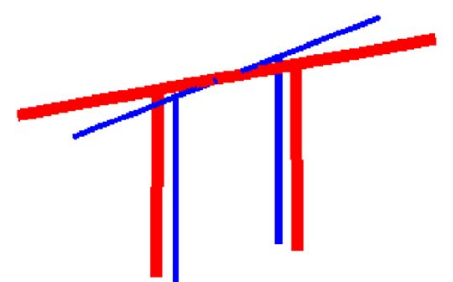

(a)

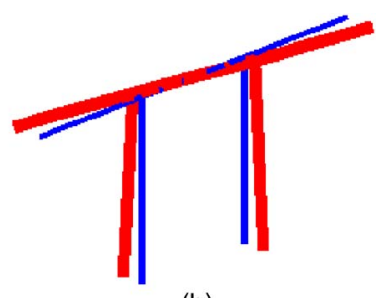

(b)
Fig. 17. Deflected shape of three-span symmetric bridge: (a) bridge without shear keys; (b) bridge with elastic shear keys column bottom moves with the ground but the top is restricted from moving due to restraint provided by the girder that is not completely free to rotate as a rigid body about the vertical axis due to restraint imposed by the shear keys at its two ends. Although results are not presented here for reasons of brevity, similar reasons led to larger deck displacement at abutments in bridges without shear keys and larger column drift in bridges with elastic shear keys for other systems considered in this investigation.

\section{Conclusions and Recommendations}

This investigation on how shear keys affect seismic behavior of bridges has led to the following conclusions:

1. The seismic demands for a bridge with nonlinear shear keys (shear keys that break off and cease to provide transverse restraint if deformed beyond a certain limit) can generally be bounded by the demand computed for two shear-key cases: elastic shear keys (shear keys that do not break off and continue to provide transverse restraint throughout the ground shaking), and no shear keys (transverse restraint due to shear keys is completely ignored). This conclusion is valid for bridges subjected to spatially uniform ground motion as well as spatially varying ground motion expected in fault-rupture zones;

2. The shear keys may be ignored in estimating an upper bound of seismic demands for a bridge subjected to spatially uniform ground motion;

3. Estimating upper bound values of seismic demands for a bridge crossing a fault-rupture zone requires analysis for two shear-key cases: no shear keys and elastic shear keys. A bridge without shear keys generally provides an upper bound estimate of deck displacement at abutment, but a bridge with elastic shear keys generally provides an upper bound estimate of column drift; and

4. Seismic response of bridges crossing fault rupture zones may be very sensitive to the strength of shear keys indicating that computation of this response, even with nonlinear RHA, may be unreliable in the absence of realistic and accurate forcedeformation models for shear keys.

Because ignoring transverse restraint due to shear keys may underestimate some seismic demands for a bridge crossing faultrupture zones, it is recommended that such bridges be analyzed 


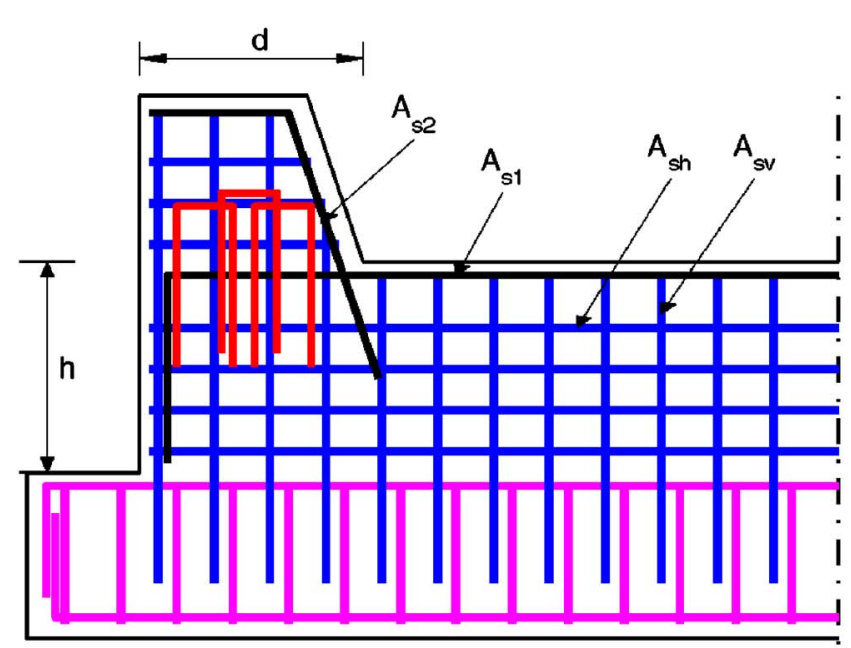

(a)

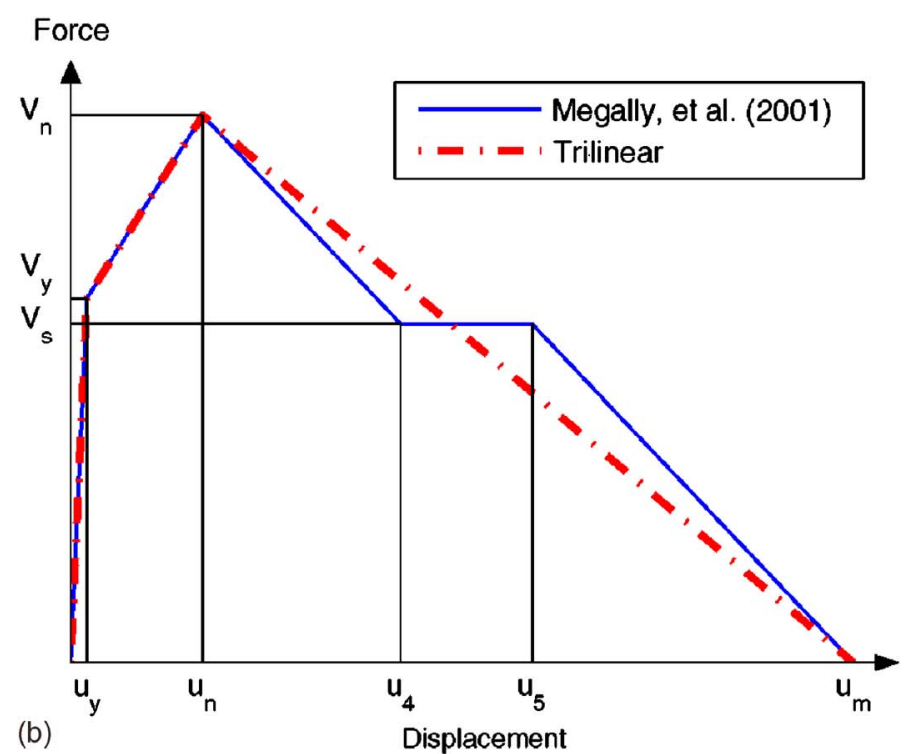

(b)

Fig. 18. (a) Shear-key details; (b) shear-key force-deformation relationship

for both shear-key cases (elastic shear keys and no shear keys) to establish an upper bound of seismic demands. Shear keys may be ignored for such bridges only if they can be demonstrated to "truly" break off before initiation of strong shaking expected during the MCE.

While explicit consideration of the nonlinear forcedeformation relationship of shear keys may be the most accurate modeling for estimating seismic demands, it presents two complications. First, some seismic demands may be underestimated if the shear key happens to be stronger than the design strength. Second, nonlinear modeling of shear keys requires that the seismic demands be determined by nonlinear RHA of the bridge system. Upper and lower bounds for seismic demands can be obtained by analyses of two simpler nonlinear systems: a bridge with elastic shear keys and a bridge without shear keys. Simplified versions of analysis procedures that avoid nonlinear RHA of these two systems will be reported separately.

\section{Acknowledgments}

The research reported in this paper is supported by CALTRANS under Contract No. 59A0435 with Dr. Mahmoud Khojasteh as the project manager. This support is gratefully acknowledged. Also acknowledged is the collaboration of Professor Douglas Dreger and Gabriel Hurtado of University of California at Berkeley, who simulated the ground motions used in this investigation. We appreciate the useful suggestions by Sami Megally of PBS\&J Inc. and Azadeh Bozorgzadeh at the University of California, San Diego on the modeling of shear keys. Comments and suggestions from anonymous reviewers also helped improve this paper.

\section{Appendix: Shear-Key Modeling}

The procedure used in this investigation to develop forcedeformation behavior of external shear keys is presented in this Appendix. For this purpose, the experimental work and the shearkey failure mechanisms reported elsewhere (Bozorgzadeh et al. 2003, 2006; Megaally et al. 2001) have been utilized. The proce- dure to evaluate the shear-key strength is presented first followed by the force-deformation relationship.

\section{Strength of Shear Keys}

Two failure mechanisms of external shear keys that are typically used by CALTRANS (Fig. 18) have been reported (see Bozorgzadeh et al. 2006 for details and other references): (1) sliding shear mechanism in which a single horizontal crack develops at the interface of the shear key and abutment stem wall; and (2) diagonal tension mechanism in which multiple diagonal cracks develop in the abutment stem wall. The nominal capacity (or strength) of the shear key in the sliding shear mechanism can be evaluated from (Bozorgzadeh et al. 2006)

$$
V_{n}=\frac{\mu_{f} \cos \alpha+\sin \alpha}{1-\mu_{f} \tan \beta} A_{v f} f_{s u}
$$

in which $\alpha=$ angle of kinking of the vertical bars with respect to the vertical axis $\left(=37^{\circ}\right) ; \beta=$ angle that includes the face of the shear key with respect to the vertical axis; $\mu_{f}=$ kinematic coefficient of friction of concrete $(=0.36)$; and $f_{s u}$ and $A_{v f}=$ ultimate tensile strength and area, respectively, of the vertical reinforcement crossing the shear plane.

The nominal capacity of the shear key in the diagonal tension mechanism can be computed from (Bozorgzadeh et al. 2006)

$$
V_{n}=V_{c}+V_{s}
$$

in which $V_{c}=$ contribution of concrete; and $V_{s}=$ contribution of steel. The value of $V_{c}$ is given by

$$
V_{c}=0.2 \sqrt{f_{c}^{\prime}} b h
$$

where $f_{c}^{\prime}=$ compressive strength of concrete (MPa); and $b$ and $h=$ width and height $(\mathrm{m})$, respectively, of the abutment stem wall. Note that units of $V_{c}$ from Eq. (4) are in MN, which can be converted to the units of $\mathrm{kN}$ by multiplying the answer from Eq. (4) by 1,000 . The contribution of steel, $V_{s}$, is given by 


$$
V_{s}=\left[A_{s 1} f_{y} h+A_{s 2} f_{y} d+n_{h} A_{\mathrm{sh}} f_{y} \frac{h^{2}}{2 s}+n_{v} A_{\mathrm{sv}} f_{y} \frac{d^{2}}{2 s}\right]\left(\frac{1}{h+a}\right)
$$

where $A_{s 1}=$ total area of the horizontal tie (or hanger) bars; $A_{s 2}=$ total area of the inclined bars in the first row crossing the shear key interface; $A_{\mathrm{sh}}$ and $A_{\mathrm{sv}}=$ area of single horizontal and vertical bars, respectively (see Fig. 18); $n_{h}$ and $n_{v}=$ number of side faces with horizontal and vertical side reinforcement, respectively; $s=$ spacing of horizontal and vertical bars; $d=$ thickness of shear key at the interface with abutment stem wall; $a=0.167 d$; and $f_{y}=$ yield strength of steel assumed to be identical for all reinforcing bars.

Under the action of a horizontal force (or shear) applied to the shear key, one of the two aforementioned mechanisms would develop in exterior shear keys. Depending on the reinforcement details and construction joint of a shear key, a mechanism that requires the lowest shear force would develop at the failure limit state.

\section{Force-Deformation Relationship of Shear Key}

In addition to the shear-key strength described in the preceding section, this investigation needed a complete description of the force-deformation relationship. While a force-deformation relationship is not currently available for the sliding shear mechanism, a simple relationship has been developed for the diagonal tension mechanism (Megally et al. 2001). In this relationship, shown in Fig. 18, the displacements at various levels are given as

$$
\begin{aligned}
& u_{y}=\sqrt{2} \varepsilon_{y}\left(L_{d}+L_{a}\right) \frac{(h+d)}{\sqrt{h^{2}+d^{2}}} \\
& u_{n}=\sqrt{2} \varepsilon_{y}\left(L_{d}+L_{a}\right) \frac{(h+d)}{s} \\
& u_{4}=\sqrt{2} \varepsilon_{0.005}\left(L_{d}+L_{a}\right) \frac{(h+d)}{s} \\
& u_{5}=\sqrt{2} \varepsilon_{0.007}\left(L_{d}+L_{a}\right) \frac{(h+d)}{s}
\end{aligned}
$$

where $\varepsilon_{y}=$ yield strain in steel; $\varepsilon_{0.005}=0.005 ; \varepsilon_{0.007}=0.007$; $L_{a}=$ width of the stem wall; and $L_{d}=$ reinforcement development length. The displacement $u_{m}$ is obtained by assuming the slope of the curve between $u_{5}$ and $u_{m}$ to be the same as that between $u_{n}$ and $u_{4}$. Finally, the force $V_{y}$ is defined as

$$
V_{y}=V_{s}+V_{c} \frac{u_{y}}{u_{n}}
$$

In this investigation, the force-deformation relationship presented by Megally et al. (2001) has been idealized by a trilinear curve (Fig. 18). The hysteretic rule, however, is similar to that presented by Megally et al. (2001). Furthermore, the forcedeformation relationship of the shear key is based only on the diagonal tension mechanism, i.e., the possibility of a sliding shear mechanism for which force-deformation relations is not currently available has been excluded. Such simplifications are not likely to significantly alter the observations and conclusions.

Development of the shear-key force-deformation relationship using the aforementioned procedure requires that the abutment design, i.e., size and reinforcement details, be available. In this parametric investigation, however, such details were not avail- able. One option was to scale experimental results from the shear key Test Unit 4A with details currently used by CALTRANS and tested at UCSD (Bozorgzadeh et al. 2006). This unit was built at 1:2.5 scale of a prototype abutment design. Therefore, the forcedeformation relationship developed for the details of the test unit using Eqs. $(6 a)-(6 d)$ and (7) was scaled as follows to obtain the force-deformation relationship of the prototype abutment: multiply the displacements and forces of the test unit by a factor of 2.5 and 6.25 , respectively. Unfortunately, the shear key in the prototype abutment obtained by such scaling was too strong (it remained essentially elastic) for the structural systems considered in this investigation.

The alternative procedure used in this investigation first selected the target strength, $V_{T}$, of the shear key to be equal to $30 \%$ of the dead load reaction at the abutment. Second, the scale factor, $s f=\sqrt{V_{T} / V_{n}}$, was computed in which $V_{n}$ was the strength of the test unit. Next, size and reinforcement details of the abutmentshear-key system in the bridge system under consideration were obtained by scaling the design of the test unit. Finally, the forcedeformation relationship was developed from Eqs. $(6 a)-(6 d)$ and (7) for the size and reinforcement details of scaled abutment design.

Note that the procedure used in this investigation to develop the force-deformation behavior of shear key may not be "accurate" theoretically; however, such a simple procedure is sufficient for this parametric investigation because the observations and conclusions are not likely to be significantly affected by the shearkey force-deformation relationship. Although results are not presented here for brevity, the force-deformation relationship of the test unit directly without any scaling led to identical observations and conclusions.

\section{References}

Bozorgzadeh, A., Megally, S., and Restrepo, J. (2003). "Seismic response of sacrificial exterior shear keys in bridge abutments: Recommended design and construction details." Rep. to CALTRANS, Contract No. 59A0337, Dept. of Structural Engineering, UC San Diego, San Diego.

Bozorgzadeh, A., Megally, S., Restrepo, J., and Ashford, S. A. (2006). "Capacity evaluation of exterior sacrificial shear keys of bridge abutments." J. Bridge Eng. 11(5), 555-565.

California Department of Transportation (CALTRANS) (2006). Seismic design criteria: Version 1.4, Sacramento, Calif., 〈http://www.dot.ca. gov $\rangle$.

Chopra, A. K. (2007). Dynamic of structures: Theory and applications to earthquake engineering, 3rd Ed., Prentice-Hall, Upper Saddle River, N.J.

Clayton, R., and Engquist, B. (1977). "Absorbing boundary conditions for acoustic and elastic wave equations." Bull. Seismol. Soc. Am., 67, $1529-1540$.

Dreger, D., Hurtado, G., Chopra, A. K., and Larson, S. (2007). "Nearfault seismic ground motions." Report No. UCB/EERC-2007/03, Earthquake Engineering Research Center, Univ. of California, Berkeley, Calif.

Larsen, S., and Schultz, C. A. (1995). "ELAS3D: 2D/3D elastic finitedifference wave propagation code." Lawrence Livermore National Laboratory Technical Rep. No. UCRL-MA-121792, Livermore, Calif.

McKenna, F., and Fenves, G. (2001). The OpenSees command language manual: Version 1.2, Pacific Earthquake Engineering Center, Univ. of California, Berkeley, Calif., 〈http://opensees.berkeley.edu〉.

Megally, S. H., Silva, P. F., and Seible, F. (2001). "Seismic response of sacrificial shear keys in bridge abutments." Rep. No. SSRP-2001/23, Dept. of Structural Engineering, Univ. of California, San Diego. 